\title{
Role of Transforming Growth Factor Signalling in Marrow Stem Cell Differentiation
}

\author{
Samina Nazarali ${ }^{1}$, Zia A. Khan ${ }^{1}$
}

${ }^{1}$ University of Western Ontario

\begin{abstract}
Bone marrow stem cells have the ability to self-renew and differentiate into a multitude of different cell types. Of the various cell potentials, the endothelial differentiation process has been the least understood due to highly context dependent methods of regulation. It was previously found that following mesodermal induction, endothelial precursors emerged in association with inhibited transforming growth factor beta (TGF $\beta$ ) signalling. To better understand the role of TGF $\beta$ signalling in the differentiation process, we treated bone marrow mononuclear cells with either a TGF $\beta$ pathway inhibitor, GW788388, or exogenous activating ligand, TGF $\beta 1$, and characterized the expression levels of various cellular markers. We demonstrate that neither treatment leads directly to an endothelial phenotype. Instead, we propose a two-step process of TGF $\beta$ and bone morphogenic protein (BMP) signalling cross-talk, that could potentially be responsible for endothelial differentiation of bone marrow derived stem cells. Our ability to derive functional endothelial cells from postnatal stem cells may impact multiple fields of research, including the study of vascular regeneration and understanding the mechanisms underlying vascular disease.
\end{abstract}

\section{Introduction}

Bone marrow contains a rich reservoir of stem cells which can self-renew, form colonies, and differentiate into a variety of mesodermal cell types in vitro. Studies have reported derivation of hematopoietic, adipogenic, chondrogenic, osteogenic and vascular endothelial cell lineages from marrow-derived stem cells (1). Of these lineages, the endothelial specification pathway is the least understood and has been the most controversial (Fig. 1) because investigators have not yet been able to reliably differentiate bone marrow stem cells into functional endothelial cells.

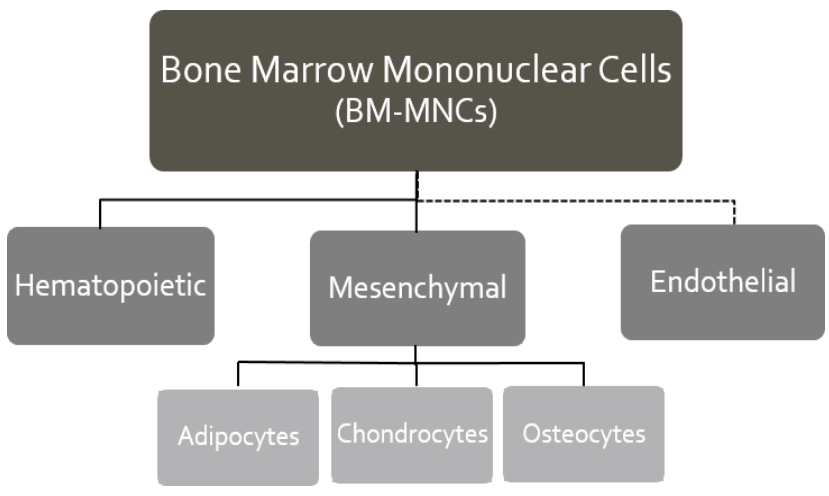

Figure 1. Differentiation potential of bone marrow mononuclear cells (BM-MNCs). Dotted line represents unknown differentiation pathway.
Unlike angiopoietins and vascular endothelial growth factors (VEGFs), which have been well documented for their effects on endothelial cell behaviour (2), transforming growth factor beta (TGF $\beta$ ) signalling was first discovered due to its effects on fibroblasts (3). Further research subsequently revealed that TGF $\beta$ affects a variety of other cell types such as stem, immune, endothelial, mural, and epithelial cells. In particular, studies aimed at investigating the signalling for gastrulation and vasculogenesis (blood vessels derived from stem cells) in vivo have demonstrated that TGF $\beta$ signalling plays a major role in allowing for the formation of endothelial precursors in the mesoderm (4-5). Furthermore, knockout mice deficient in various TGF $\beta$ superfamily components exhibited defects in vascular tissues (6). Extensive phenotypic and molecular characterization of the mice found that TGF $\beta$ signalling plays a pivotal role in the process of angiogenesis, and has directly linked numerous cardiovascular defects to mutations in key signalling components (7). Figure 1. Differentiation potential of bone marrow mononuclear cells (BM-MNCs). Dotted line represents unknown differentiation pathway.

The first known member of the TGF $\beta$ superfamily of secreted polypeptide factors, was TGF $\beta 1$. It was discovered approximately thirty years ago, and since then, the family has grown considerably and now comprises of over thirty members, which are characterised as multifunctional cytokines involved in the regulation of proliferation, differentiation, migration, and survival of a multitude of cell types (8). TGF $\beta$ is first produced in a latent 
form and must be activated by either thrombospondin or proteases, consequently allowing it to bind to type I and type II transmembrane kinase receptors (9). The TGF $\beta$ signalling pathway specifically involves a single type II receptor (T $\beta R$-II) and two individual type I receptors; the endothelial restricted activin receptor-like kinase 1 (ALK1) and the more widely expressed activin receptor-like kinase 5 (ALK5). The general structures of the receptors are similar, as both type I and type II are composed of cysteine-rich extracellular domains, single transmembrane regions, and intracellular components which contain serine/threonine kinase domains. Of the two receptors, TGF $\beta$ has a higher affinity for T $\beta R$-II, and once bound, either ALK1 or ALK5 is recruited (11). Following the generation of the ligand induced heteromeric complex, the conserved thirty amino acid glycine and serine rich region, known as the GS domain of the type I receptor is phosphorylated by the constitutively active type II receptor, resulting in a conformational change of ALK1/ALK5. Subsequently, phosphorylation of signalling molecules by the kinase domain of the receptor, allows for the signal to be propagated to the nucleus, resulting in a diversity of cellular responses (12).

TGF $\beta$ signalling demonstrates complex regulation which relies on highly context dependent properties such as the differentiation state of the cell and the presence of other specific extracellular cues. This has resulted in conflicting reports on the regulation of TGF $\beta$ signalling, making it difficult to elucidate the role of this pathway in the process of endothelial differentiation. In vivo studies initially indicated that TGF $\beta$ signalling inhibits endothelial proliferation and migration while stimulating the differentiation of cells into mesenchymal phenotypes, more specifically to pericytes and smooth muscle cells. (13-15). However, stimulatory effects of TGF $\beta$ have also been reported on angiogenesis in vivo (1, 16-17). Additionally, further studies have shown that the loss of TGF $\beta$ signalling components such as ALK1, ALK5, and T $\beta R$-II leads to abnormal formation of vasculature and decreased wall integrity due to impaired differentiation (6). These opposing results may suggest that a balance of positive and negative effects of TGF $\beta$ signalling at the appropriate time and cellular context is crucial, and could provide a potential method of regulation for endothelial differentiation. A recent study, aimed at trying to understand the seemingly dual effect that TGF $\beta$ has on the differentiation process, found that following mesodermal induction, CD34 positive (a cellular marker indicative of the endothelial phenotype) cells emerged in association with inhibited transforming growth factor signalling (18). Therefore, we hypothesize that the inhibition of transforming growth factor signalling will lead to endothelial differentiation while activation of the pathway will inhibit endothelial differentiation of bone marrow derived stem cells.

The purpose of the current study was to develop a further understanding of endothelial specification from marrow derived stem cells by examining the role of transforming growth factor signalling on the differentiation process. To gain further insight into this pathway, we investigated the expression of cellular markers in bone marrow mononuclear cells which were cultured in the presence of a TGF $\beta$ signalling inhibitor (GW788388, herein referred to as $\mathrm{GW}$ ) or treated with exogenous TGF $\beta 1$ ligand, which effectively stimulated the signalling pathway in comparison to a negative, untreated control population.

Further understanding the role of TGF $\beta$ signalling in endothelial differentiation may elucidate previously unknown mechanisms of regulation which could underline various vascular pathologies. Furthermore, the potential ability to derive functional endothelial cells from post-natal stem cells will impact multiple research fields, including the study of vascular regeneration and disease.

\section{Methods \\ Cell culture}

Bone marrow mononuclear cells from a single donor were plated and cultured in a 12-well plate, with endothelial basal media-2 (EBM2; Lonza Inc.) supplemented with $20 \%$ fetal bovine serum (FBS; CA-95042-112; Lonza Inc.), EBM2 SingleQuots (Lonza Inc.) and $1 \mathrm{x}$ antibiotic antimycotic media (CA45000-616; Mediatech Inc.). Cells were further divided into one negative control and two treatment groups. The first treatment group was treated with the addition of $10 \mathrm{ng} / \mathrm{mL}$ TGF $\beta 1$ while the second was treated with a potent TGF $\beta$ signalling inhibitor, GW788388 $(1 \mu \mathrm{M})$. There were three total replicates for each of the groups, which were all cultured for a total of 14 days.

\section{cDNA synthesis}

Following the 14-day cell culture, total RNA was extracted from the 9 samples using the RNeasy Mini Kit (Qiagen) which uses a column based extraction method. The purity of the samples was assessed by determining the concentration using the Qubit Fluorometer (Life Technologies). The RNA volumes were adjusted using the concentration 
readings, and a total of $25 \mathrm{ng}$ RNA for each of the samples was subsequently used in the cDNA synthesis protocol using the iScript cDNA Synthesis Kit (Bio Rad).

\section{PCR}

The induction of genes associated with three of the potential fates of bone marrow stem cells were quantified using PCR. Primers of Oct4 and SOX2 were used as markers of the differentiation potential of the cells. CD72, CD90, CD105 and aSMA were used as markers of mesenchymal expression. Finally, endothelial markers VE-Cadherin and CD31 were detected. Beta-actin, a housekeeping gene, was used as the internal control for the PCR protocol. Each of the samples were run using the same set of primers to allow for comparisons between condition groups. The wells in the PCR plate contained the associated primers for the gene of interest, the appropriate DNA template (all 9 samples were tested), and the necessary reagents for the PCR protocol (Qiagen). All reactions were performed for 30 cycles with temperature and time profiles as follows: initiation $\left(95^{\circ} \mathrm{C}\right.$ for 3 minutes, followed by 30 seconds per cycle following the initial cycle), annealing $\left(55^{\circ} \mathrm{C}\right.$ for 45 seconds) and extension ( $72^{\circ} \mathrm{C}$ for 45 seconds).

\section{Data analysis}

The fluorescence of the genes of interest was measured (BioRad CFX Manager) as a result of the fluorescent marker SYBR binding to the double stranded DNA after each cycle of PCR. Data was normalized by using the fluorescence reading of $\beta$ actin for each of the samples and dividing it by the fluorescence of the gene of interest to account for the RNA quantity. Furthermore, melt curves of each sample were analyzed to ensure the correct amplicons were detected and to evaluate the purity of samples. Student's two tailed t-test $(p<0.05)$ was performed (using triplicates) to evaluate the differences in gene expression between the treated and the control group.

\section{Results}

\section{TGF $\beta$ inhibition does not directly induce endothelial differentiation}

Bone marrow mononuclear cells treated with GW, a potent inhibitor of TGF $\beta$ signalling, which specifically inhibits the TGF $\beta$ type I receptor, did not show a significant difference in the expression of SOX2 and Oct4 (Fig. 2A). Both are markers of differentiation potential, indicating that TGF $\beta$ inhibition does not impact the differentiation capacity of the cells. However, there was a significant decrease of VE-Cadherin along with a decrease in expression of CD31 compared with the control (Fig. 2B). VE-Cadherin and CD31 are both endothelial markers, indicating that inhibition of the TGF $\beta$ signalling pathway does not lead directly to an endothelial phenotype as initially proposed. Further examination of mesenchymal markers, revealed a decrease in expression of all tested markers in the treatment group compared with the control, except for CD73, which was upregulated in GW treated cells (Fig. 2C). CD73 is a general marker for mesenchymal differentiation, but may also be associated with the hematopoietic phenotype. Since all other mesenchymal markers were shown to be downregulated in cells with inhibited TGF $\beta$ signalling, it may be possible that the cells are moving towards a hematopoietic phenotype. To further validate this, a long-term study, which would provide a larger RNA sample, could be used to obtain expression data of a wider variety of hematopoietic markers such as CD45, RUNX1, and GATA2, in addition to the markers used in the current study. This would allow for a more reliable conclusion of hematopoietic phenotype emerging from cells with inhibited TGF $\beta$ signalling.

\section{TGF $\beta$ signalling inhibits endothelial differentiation while promoting mesenchymal differentiation}

Cells treated with exogenous TGF $\beta 1$ ligand, thus experiencing activation of the transforming growth factor signalling pathway, demonstrated no significant difference in the expression of stem cell markers, SOX2 and Oct4 in comparison with the control (Fig. 3A). TGF $\beta 1$ was used as the ligand as opposed to the other TGF $\beta$ isoforms, due to its greater affinity for $T \beta R$-II. As initially expected, there was a significant reduction in the expression levels of both endothelial markers, with a complete shutdown of VE-Cadherin expression (Fig. 3B), indicating that TGF $\beta$ signalling does indeed inhibit endothelial differentiation. Furthermore, a-SMA, a mesenchymal marker was upregulated in cells with exogenously activated TGF $\beta$ signalling compared with the control cell population (Fig. $3 C$ ). This suggests that TGF $\beta$ signalling may lead to mesenchymal differentiation, more specifically, smooth muscle differentiation, as a-SMA is a marker of myofibroblast formation. This is consistent with previous literature stating that TGF $\beta$ signalling may lead to the formation of pericytes and smooth muscle cells (13-15). The bone marrow mononuclear cells used in the current study 
A)

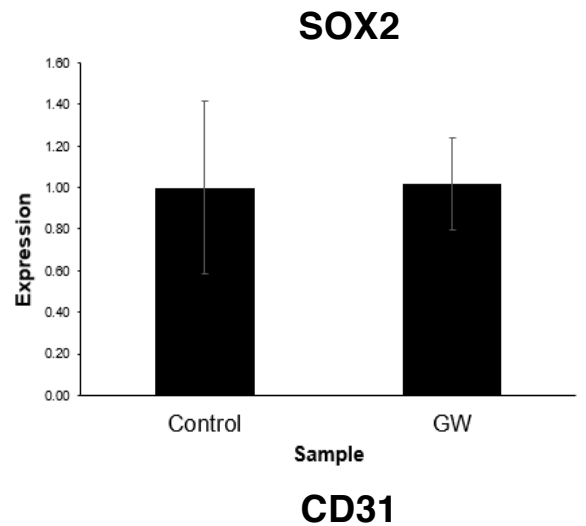

B)

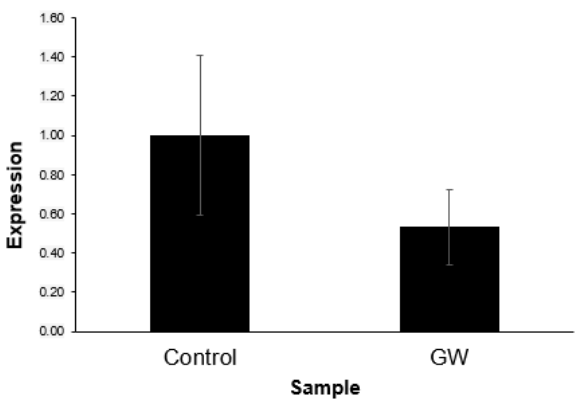

C)

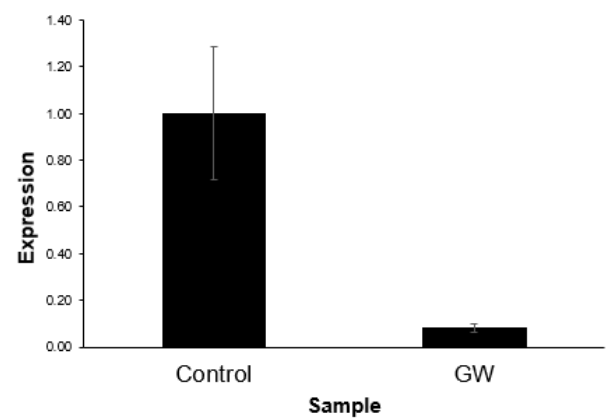

CD105

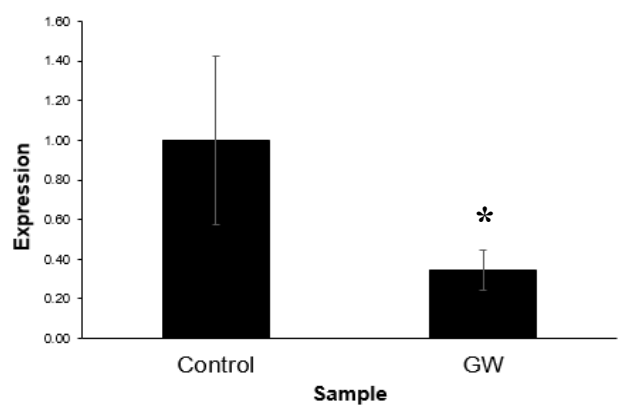

Oct4

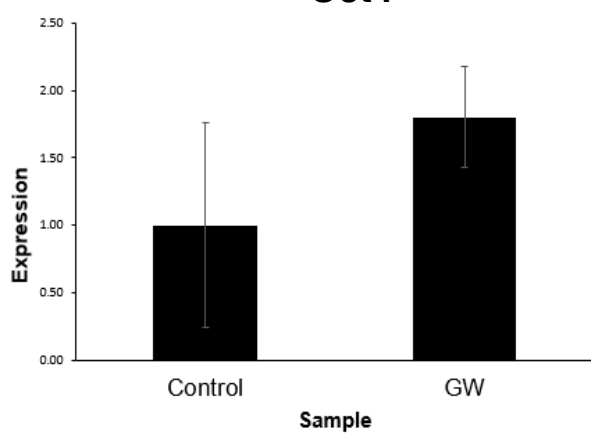

VE-Cadherin

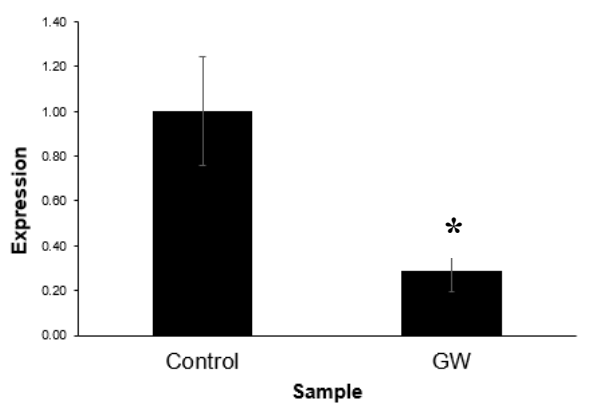

aSMA

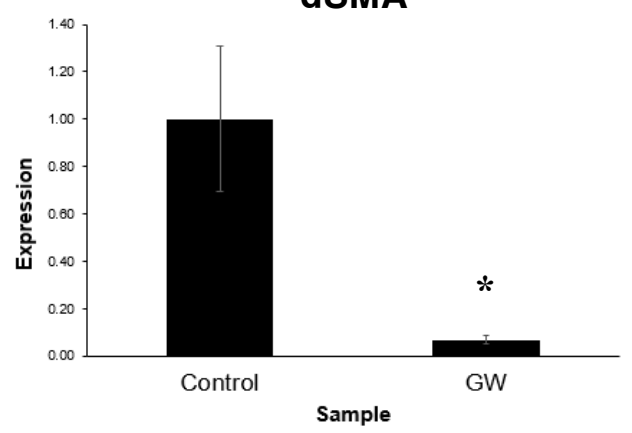

CD73

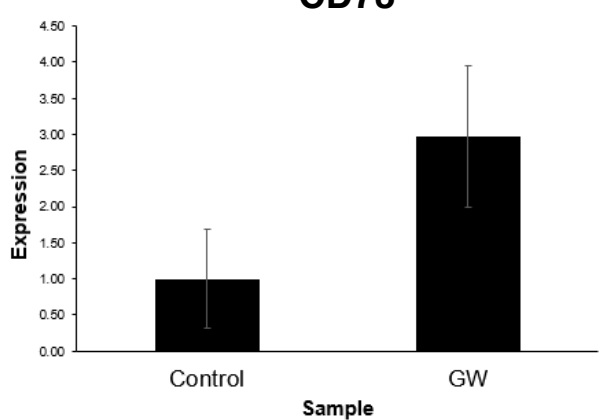

Figure 2. Normalized expression levels of cellular markers in GW treated cells compared with control. A) stem cell differentiation markers B) endothelial markers C) mesenchymal markers. Expression data normalized with fluorescence readings of $\beta$-actin, and all expression values are considered relative to the negative control. Asterisks denote expression levels of cellular markers which are significantly different than the expression levels of the control group (Student's two-tailed t-test): ${ }^{*} \mathrm{P}<0.05$. Error bars are normalized SD. 
Figure 3

A)

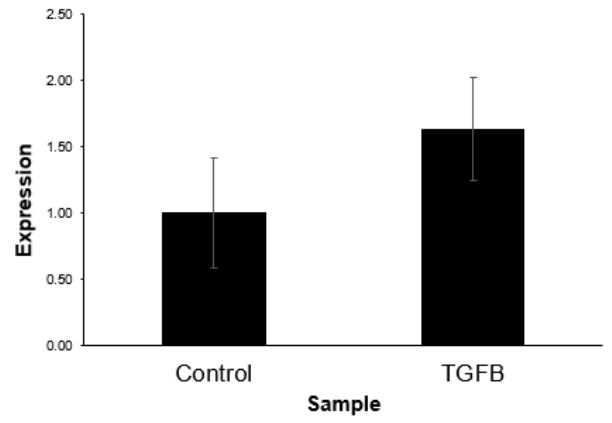

CD31

B)

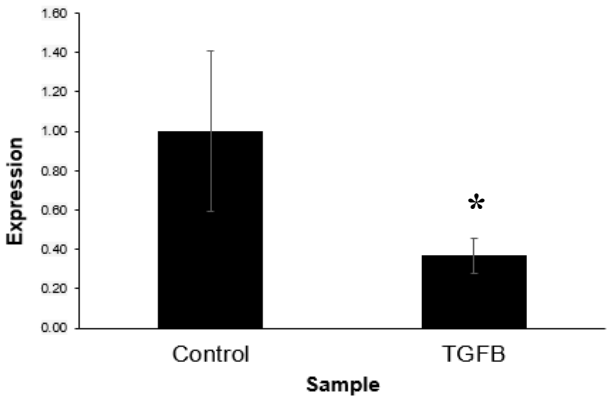

THY1/CD90

C)

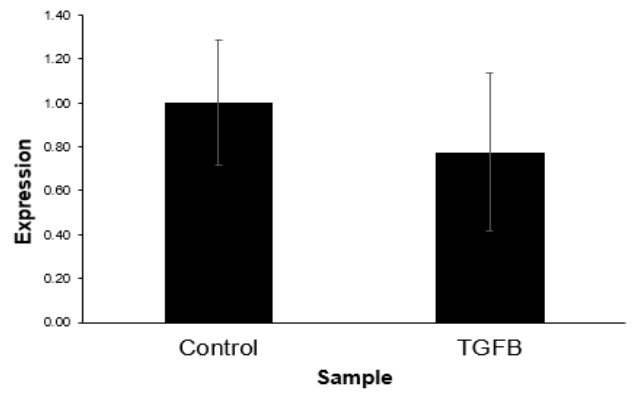

CD105

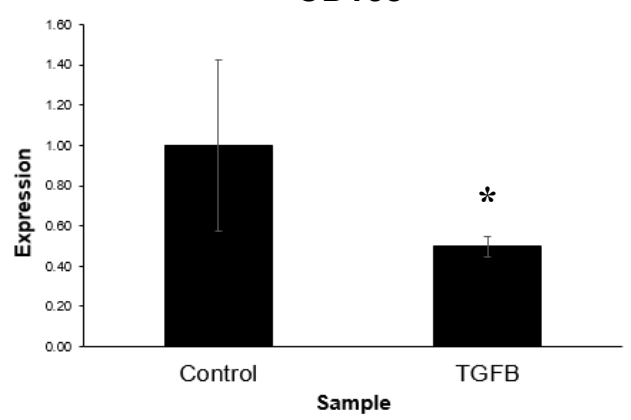

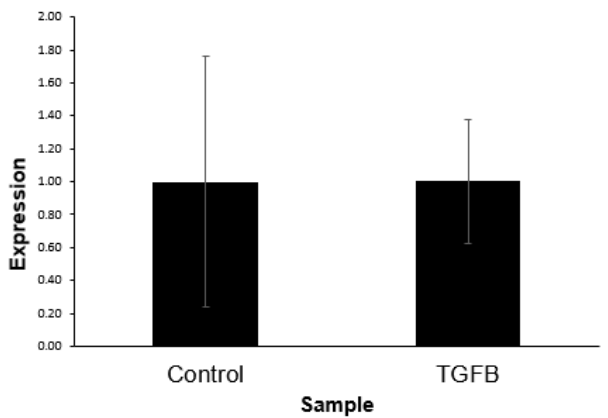

VE-Cadherin
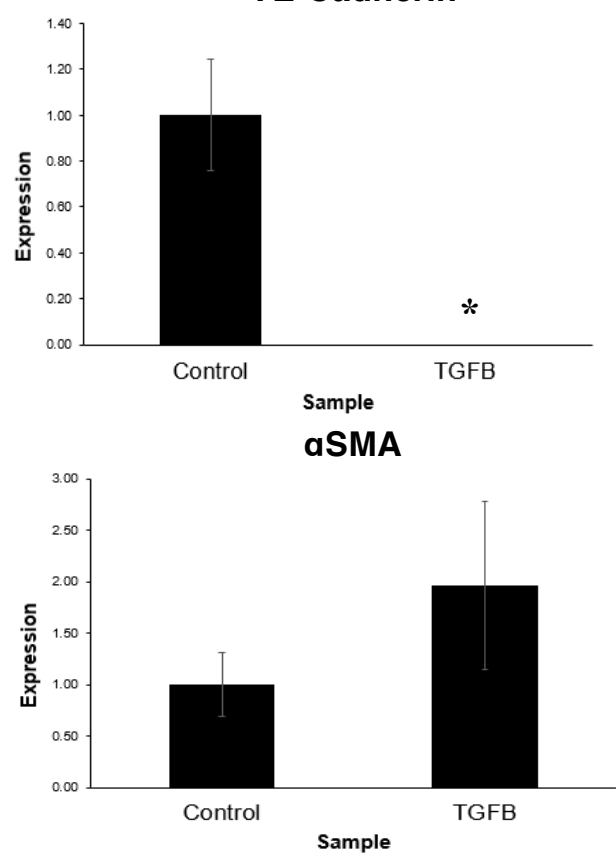

CD73

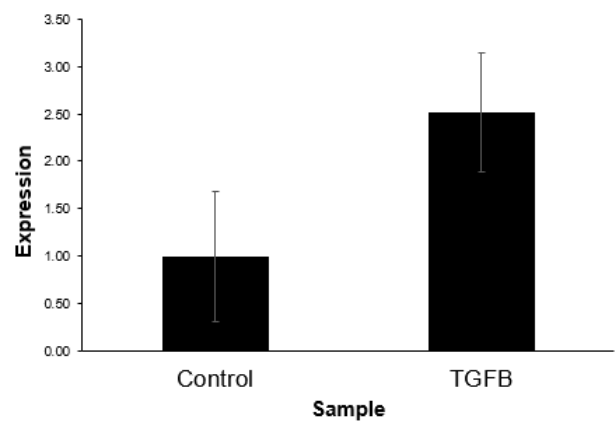

Figure 3. Normalized expression levels of cellular markers in TGF $\beta 1$ treated cells compared with control. A) stem cell differentiation markers B) endothelial markers C) mesenchymal markers. Expression data normalized with fluorescence readings of $\beta$-actin, and all expression values are considered relative to the negative control. Asterisks denote expression levels of cellular markers which are significantly different than the expression levels of the control group (Student's two-tailed t-test): ${ }^{*} \mathrm{P}<0.05$. Error bars are normalized SD. 
were obtained from a single donor, which may present inherent limitations within the study. To further validate the discussed results, more diverse replicates would be required. Repeating this experiment with a long-term culture of BM-MNCs treated with exogenous TGF $\beta 1$ in the future, would allow us to isolate RNA at various time points and monitor the expression levels of cellular markers of interest over time to ensure the results. Based on the results of the current study, we would expect that mesenchymal marker expression (namely aSMA, which is considered a reliable maker for distinguishing between smooth muscle and endothelial cells) would continue to increase, while the expression.

\section{Discussion}

As expected, TGF $\beta$ signalling seems to inhibit endothelial differentiation while promoting cells to follow a mesenchymal lineage; however, TGF $\beta$ inhibition did not directly lead to an increased expression of endothelial markers as initially predicted. Thus, there remains a gap in knowledge, as to what signalling pathway(s) and regulation mechanisms cause marrow stem cells to differentiate into an endothelial phenotype.

\section{Concentration dependent regulation}

Mutations in genes encoding for components of the TGF $\beta$ pathway are linked to numerous vascular pathologies, underscoring the importance of TGF $\beta$ signalling in the process of endothelial cell differentiation. In vitro studies have also highlighted the functional effects that TGF $\beta$ signalling has on the endothelial cells such as regulating proliferation, differentiation, migration, and extracellular matrix production (19). However, the mechanisms of TGF $\beta$ signalling remain unknown. Results obtained by different laboratories aimed at understanding the regulative and mechanistic role of TGF $\beta$ signalling are sometimes in apparent conflict. This can largely be credited to a context, and perhaps, even a concentration dependent method of regulation which may explain why neither treatment in the current study led directly to an endothelial phenotype.

The TGF $\beta$ receptor complex transmits signals through many factors such as Smad 2/3, TGF $\beta$-activated kinase 1 (TAK1), and phosphoinositide 3-kinase (P13K), leading to various cellular activities such as cell migration, angiogenesis, and mesenchymal transition. The Smad 2/3 pathway in particular, has been implicated in mesenchymal transition $(9,20)$ and is activated by the ALK5 type I receptor. A high level of activation, such as when we added exogenous TGF $\beta 1$ to cell samples, may effectively stimulate a sub-cellular pathway which leads to mesenchymal differentiation (potentially the Smad 2/3 pathway), and indirectly inhibits the cell from following the endothelial lineage. Furthermore, reports suggest that high TGF $\beta$ stimulation induces expression of plasminogen activator inhibitor type 1 (PAI-1), a negative regulator of endothelial cell differentiation and migration (21), further demonstrating the potential for a concentration based regulation system. Conversely, by treating cells with $\mathrm{GW}$, and effectively blocking the TGF $\beta$ signalling pathway, we may have left cells in an intermediate stage as they exhibited low expression of both mesenchymal and endothelial cell markers in comparison to negative control cells. Thus, there might be a missing signal which is required to transform cells with low mesenchymal marker expression into functional endothelial cells.

A future extension of the current study would be to further understand the roles of the subcellular TGF $\beta$ pathways as they currently remain unclear. By treating BM-MNCs with exogenous TGF $\beta 1$ ligand, and using inhibitors of each of the sub-cellular pathways, we would be able to observe the differences between the expected results, as obtained in this study (increased expression of mesenchymal markers) to the expression levels of cells treated with inhibitors. This would allow for a better understanding of which sub-cellular pathway(s) may be required for mesenchymal transition and thus, would be activated as a result of TGF $\beta$ signalling stimulation.

\section{BMP4: the cross talk between pathways}

In the current study, we examined the role of TGF $\beta$ signalling in the process of endothelial differentiation; however, biological pathways often do not act in isolation. The TGF $\beta$ pathway relies heavily on its communication with other signalling networks in order to achieve appropriate biological responses. Thus, signalling cross-talk is a central theme of TGF $\beta$ research, and in particular, TGF $\beta$ has been shown to have close links to the bone morphogenic protein (BMP) pathway through interactions with Smad proteins. BMPs belong to the TGF $\beta$ superfamily of proteins and specifically activate bone morphogenic type II protein receptors, BMPRII. The signalling cascade, similar to that of TGF $\beta$ signalling, is known to initiate a different Smad 1/5/8 pathway, which when phosphorylated, has been shown to have important functions in adult vascular endothelium 
development and promoting angiogenesis (22). Furthermore, dysregulated BMP signalling has been linked to vascular disease indicating that it may also have a role in endothelial differentiation and proliferation.

A recent study aimed at identifying the factors required for endothelial differentiation found that cells require VEGF and BMP4 (23). VEGF is a potent angiogenic factor, which was supplemented in the endothelial basal media used for the cell culture protocol in the current study, and it is well documented for its role as an endothelial cell-specific mitogen and as a regulator of angiogenesis. However, BMP4 was not added to the culture, and could likely be the missing signal required for GW treated cells to differentiate into endothelial cells. This could potentially bridge the gap between the TGF $\beta$ and BMP pathways in the process of endothelial cell differentiation from bone marrow derived stem cells.

This finding may suggest a two-fold process in which the TGF $\beta$ signalling pathway must be inhibited to ensure that cells maintain low mesenchymal marker expression levels and do not follow the suggested Smad 2/3 pathway. Cells must then be further supplemented with BMP4 to activate the bone morphogenic protein pathway which initiates Smad 1/5/8. The relevance of the suggested pathway could be tested in the future by using BMMNCs cultured in EBM2 (supplemented with VEGF), treated with GW and BMP4. The expression of various endothelial and mesenchymal markers would have to be tracked over different time points to test for endothelial differentiation.

\section{Applications}

TGF $\beta$ and BMP signalling are involved in a diversity of cellular processes and are fundamentally important during all stages of development. Deregulation of TGF $\beta / B M P$ activity can lead to various developmental defects and diseases, including cancer. In addition, multiple vascular disorders have been linked to alterations in the TGF $\beta / B M P$ signalling pathways. Hemorrhagic telangiectasia (HHT) is one such disorder, and in vivo studies have shown that endothelial specific deletion of the ALK1 receptor, causes vascular irregularities which mimic the pathological characteristics of HHT2 vascular lesions (24). Clinically, HHT is characterized by various symptoms including arteriovenous irregularities in pulmonary, cerebral, and/or hepatic circulation (25). Since all genes implicated in HHT code for proteins which are part of the TGF $\beta$ pathway, understanding signalling regulation is crucial for establishing the relationship between the genes affected by mutation in HHT patients and the disease itself. In addition, pulmonary arterial hyperplasia (PAH) has been related to mutations in the BMPRII gene (26) and is characterized by abnormal endothelial cell growth and maintenance. PAH causes an increase in arterial pressure, occlusions in pulmonary arteries, and can even lead to heart failure. With TGF $\beta$ and BMP signalling deregulation at the core of many cardiovascular disorders, the individualsignalling components of these pathways may represent potential targets for therapy. Thus, an increased understanding of the endothelial differentiation pathway and the role of TGF $\beta$ and BMP signalling in this process could allow for the identification of the underlying mechanisms for these, and other, vascular pathologies. Additionally, bone marrow derived stem cells may also provide potential regeneration options, due to the relative ease of isolating post-natal bone marrow cells paired with the great plasticity of these cells. Clinical trials for Osteogenesis Imperfecta (27) and Hurler's syndrome (28) have already proven the importance of transplanted bone marrow stem cells and this could lead to possible vascular regeneration therapies in the future.

\section{References}

1. Pittenger MF, Mackay AM, Beck SC, Jaiswal RK, Douglas R, Mosca JD, Moorman MA, Simonetti DW, Craig S, Marshak DR. Multilineage potential of adult human mesenchymal stem cells. Science. 1999; 284(5411):143-147. DOI: 10.1126/science.284.5411.143

2. Adams $\mathrm{RH}$, Alitalo K. Molecular regulation of angiogenesis and lymphangiogenesis. Nat Rev Mol Cell Biol. 2007; 8(6):464-478. DOI: $10.1038 / \mathrm{nrm} 2183$

3. Roberts AB, Sporn MB, Assoian RK, Smith JM, Roche NS, Wakefield LM, Heine UI, Liotta LA, Falanga V, Kehrl JH. Transforming growth factor beta: rapid induction of fibrosis and angiogenesis in vivo and stimulation of collagen formation in vitro. Proc Natl Acad Sci USA. 1986; 83(12):4167-4171. DOI: 10.1073/pnas.83.12.4167

4. Frater-Schroder $M$, Muller $G$, Birchmeier $W$, Bohlen $P$. Transforming growth factor-beta inhibits endothelial cell proliferation. Biochem Biophys Res Commun. 1986; 137(1):295-302. DOI: 10.1016/0006-291x(86)91209-x

5. Cross MJ, Claesson-Welsh L. FGF and VEGF function in angiogenesis: signalling pathways, biological responses and therapeutic inhibition. Trends Pharmacol Sci. 2001; 22(4):201207. DOI: 10.1016/s0165-6147(00)01676-x

6. Goumans MJ, Mummery C. Functional analysis of the TGFbeta receptor/Smad pathway through gene ablation in mice. Int J Dev Biol. 2000; 44(3):253-265. DOI: 10.1016/s0165-6147(00)01676- x

7. Bujak M, Frangogiannis NG. The role of TGF-beta signalling in myocardial infarction and cardiac remodeling. Cardiovasc 
Res. 2007; 74(2):185-195. DOI: 10.1016/j.cardiores.2006.10. 002

8. Roberts $A B$, McCune BK, Sporn MB. TGF-beta: regulation of extracellular matrix. Kidney Int. 1992; 41(3):557-559. DOI: 10.1038/ki.1992.81

9. Derynck R, Zhang YE. Smad-dependent and Smadindependent pathways in TGF-beta family signalling. Nature. 2003; 425(6958):577-584. DOI: 10.1038/nature02006

10. Goumans MJ, Valdimarsdottir G, Itoh S, Rosendahl A, Sideras $P$, ten Dijke $P$. Balancing the activation state of the endothelium via two distinct TGF-beta type I receptors. EMBO J. 2002; 21(7)1743-1753. DOI: 10.1093/emboj/21.7.1743

11. Lebrin F, Deckers M, Bertolino P, ten Dijke P. TGF-B receptor function in the endothelium. Cardiovasc Res. 2005; 65(3):599608. DOI: 10.1016/j.cardiores.2004.10.036

12. Wieser R, Wrana JL, Massague J. GS domain mutations that constitutively activate $\mathrm{T}$ beta $\mathrm{RI}$, the downstream signaling component in the TGF-beta receptor complex. EMBO J. 1995; 14(10): 2199-2208.

13. Guo $X$, Chen SY. Transforming growth factor- $\beta$ and smooth muscle differentiation. World J Biol Chem. 2012; 3(3):41-52. DOI: 10.4331/wjbc.v3.i3.41

14. Madri JA, Bell L, Merwin JR. Modulation of vascular cell behaviour by transforming growth factors beta. Mol Reprod Dev. 1992; 32(2):121-126. DOI: 10.1002/mrd.1080320207

15. Hirschi KK, Rohovsky SA, D'Amore PA. PDGF, TGF-beta, and heterotypic cell-cell interactions mediated endothelial cellinduced recruitment of $10 \mathrm{~T} 1 / 2$ cells and their differentiation to a smooth muscle fate. J Cell Biol. 1998; 141(3):805-814. DOI: 10.1083/jcb.141.3.805

16. Yang EY, Moses HL. Transforming growth factor beta 1 induced changes in cell migration, proliferation, and angiogenesis in the chicken chorioallantoic membrane. J Cell Bio. 1990; 111(2):731-741. DOI: 10.1083/jcb.111.2.731

17. Koh GY, Kim SH, Klug MG, Park K, Soonpaa MH, Field LJ. Targeted expression of transforming growth factor-beta 1 in intracardiac grafts promotes vascular endothelial cell DNA synthesis. J Clin Invest. 1995; 95(1):114-121. DOI: 10.1172/JCl117627

18. Bai $H$, Xie $Y L$, Gao $Y X$, Cheng $T$, Wang ZZ. The balance of positive and negative effects of TGF- $\beta$ signalling regulates the development of hematopoietic and endothelial progenitors in human pluripotent stem cells. Stem Cells Dev. 2013; 22(20):2765-2776. DOI: 10.1089/ scd.2013.0008

19. Goumans MJ, Liu Z, ten Dijke P. TGF-beta signalling in vascular biology and dysfunction. Cell Res. 2009;19(1):116127. DOI: $10.1038 / \mathrm{cr} .2008 .326$.
20. Furumatsu T, Tsuda M, Taniguchi N, Tajima Y, Asahara $\mathrm{H}$. Smad3 induces chondrogenesis through the activation of SOX9 via CREB-binding protein/p300 recruitment. J Biol Chem. 2005;280(9) 8343-8350, DOI: 10.1074/jbc.M413913200

21. Stefansson S, Lawrence DA. The serpin PAl-1 inhibits cell migration by blocking integrin alpha $\mathrm{V}$ beta 3 binding to vitronectin. Nature. 1996; 383(6599):441-443. DOI: 10.1038/ $383441 \mathrm{a} 0$

22. Valdimarsdottir G, Goumans MJ, Rosendahl A, Brugman M, Itoh S, Lebrin F, Sideras P, ten Dijke P. Stimulation of Id1 expression by bone morphogenetic protein is sufficient and necessary for bone morphogenetic protein-induced activation of endothelial cells. Circulation. 2002; 106(17):2263-2270. DOI: 10.1161/01.cir.0000033830.36431.46

23. Prasain N, Lee MR, Vemula S, Meador JL, Yoshimoto $M$, Ferkowicz MJ, Fett A, Gupta M, Rapp BM, Saadatzadeh MR, Ginsberg M, Elemento O, Lee Y, Voytik-Harbin SL, Chung HM, Hong KS, Reid E, O'Neill CL, Medina RJ, Stitt AW, Murphy MP, Rafii S, Broxmeyer HE, Yoder MC. Differentiation of human pluripotent stem cells to cells similar to cord-blood endothelial colony-forming cells. Nat Biotechnol. 2014; 32(11):1151-1157. DOI: 10.1038/nbt.3048

24. Johnson DW, Berg JN, Baldwin MA, Gallione CJ, Marondel I, Yoon SJ, Stenzel TT, Speer M, Pericak-Vance MA, Diamond A, Guttmacher AE, Jackson CE, Attisano L, Kucherlapati R, Porteous ME, Marchuk DA. Mutations in the activin receptorlike kinase 1 gene in hereditary haemorrhagic telangiectasia type 2. Nat Genet. 1996; 13(2): 189-195. DOI: 10.1038/ng0696-189

25. Shovlin CL, Letarte M. Hereditary haemorrhagic telangiectasia and pulmonary arteriovenous malformations: issues in clinical management and review of pathogenic mechanisms. Thorax. 1999; 54(8):714-729. DOI: 10.1136/thx.54.8.714

26. West J, Fagan K, Steudel W, Fouty B, Lane K, Harral J, HoedtMiller M, Tada Y, Ozimek J, Tuder R, Rodman DM. Pulmonary hypertension in transgenic mice expressing a dominantnegative BMPRII gene in smooth muscle. Circ Res. 2004; $\quad$ 94(8):1109-1114. 10.1161/01.res.0000126047.82846.20

27. Horwitz EM, Prockop DJ, Fitzpatrick LA, Koo WW, Gordon PL, Neel M, Sussman M, Orchard P, Marx JC, Pyeritz RE, Brenner MK. Transplantability and therapeutic effects of bone marrowderived mesenchymal cells in children with osteogenesis imperfecta. Nat Med. 1999; 5(3):309-313. DOI: 10.1038/6529 28. Koc ON, Day J, Nieder M, Gerson SL, Lazarus HM, Krivit W. Allogeneic mesenchymal stem cell infusion for treatment of metachromatic leukodystrophy (MLD) and Hurler syndrome (MPSIH). Bone Marrow Transplant. 2002; 30(4):215-222. DOI: $10.1038 /$ sj.bmt. 1703650 